\title{
A BICICLETA QUE TINHA BIGODES' E A CARTA DO MENINO N
}

Izabel Cristina da Rosa Gomes dos Santos

Resumo: O presente texto propõe desvelar o lugar da infância a partir das crianças narradoras apresentadas pelo escritor angolano Ondjaki. O estudo propõe-se a um diálogo com a obra literária $A$ Bicicleta Que Tinha Bigodes(2012) e a pluralidade da infância presente nas discussões de Larrosa (2004), Kohan (2010), Kramer (2009). Nesse sentido, ancorou- se em uma escolha metodológica a partir das contribuições das diferentes áreas do conhecimento e suas relações com a infância. Ressalta-se, também, as contribuições do pensamento africano acerca do cuidado de si e do outro, ou seja, uma ética da sensibilidade, constituída pelo equilíbrio das relações de existência, pois há seres coisas e há seres humanos que se harmonizam em convivência plena. Ainda por este estudo, evidenciou-se o que a literatura provoca-nos a pensar acerca das infâncias, da alteridade e da ancestralidade. A ideia central deste texto pauta-se em uma permeabilidade conceitual que possa ser aporte para pensar qual é o lugar da infância, a partir das imagens literárias da obra mencionada e do contexto angolano de resgate de afetos e defesa de um poder político pós-independência que se assentava como hostil e belicoso. Talvez também seja possível pensar que a importância da infância seja equivalente a um resgate da utopia, tal como a revolução foi a utopia da geração anterior aos anos 80 . Essas escolhas, em busca de entrecruzar literatura e infância, permitiram um olhar ao que diz o Menino $N$, ou menino narrador, em narrativas de uma infância vivida em Angola, em um momento histórico marcado pela guerra civil e pela presença soviética e cubana em Angola. Importa dizer de um narrar a vida ainda em estado de infância.

Palavras-chave: Infância. Menino N. Ondjaki.

Abstract: This text proposes to unveil the place of childhood from the narrator children presented by the Angolan writer Ondjaki. The study proposes a dialogue with the book A Bicicleta que Tinha Bigodes (2012) and the plurality of childhood present in the discussions of Larrosa (2004), Kohan (2010), Kramer (2009). In this sense, it was based on a 
methodological choice based on contributions from different areas of knowledge and their relationship with childhood. It also emphasizes the contributions of the african thoughts on the selfcare and the care for others, that is, an ethics of sensibility, constituted by the balance of the relations of existence, as there are things and there are human beings who harmonize in full coexistence. Also in this study, it became clear what the literature provokes us to think about childhoods, alterity and ancestry. The central idea of this text is based on a conceptual permeability that can be used to think about the place of childhood, based on the literary images of the mentioned work and the angolan context of rescuing affections and defending a post-independence political power who settled as hostile and bellicose. Perhaps it is also possible to think that the importance of childhood is equivalent to a rescue of utopia, just as the revolution was the utopia of the generation before the 1980s. These choices, in effort to crosslink literature and childhood, allowed a view of Menino $N$, or narrator boy, in narratives of a childhood lived in Angola, in a historical moment marked by the civil war and the Soviet and Cuban presence in Angola. It is important to say about a narration of life still in a state of infancy.

Keywords: Childhood. Menino N. Ondjaki.

\section{Entre tramas e percursos africanos}

Vou caminhar em frente até que atinja o mar. Não este mar que vejo à retaguarda, donde nos vem a brisa laminar das tardes de setembro, menor do céu de bruma que nos maninha o chão.

Eu vou seguir em frente e ultrapassar o paredão das serras, a cortina das águas que na distância acende a redobrada angústia de uma possível esperança. [...] Vou caminhar em frente e procurar o espelho de outras águas, como se fosse a última estação e eu nunca mais morresse ao pôr do sol no ventre insaciável das viagens. (CARVALHO, 1976, p. 55) 
E o mar está em frente, indica uma separação geográfica entre o continente africano e o Brasil. Acredito ${ }^{1}$ que o mais acertado seria dizer que o mar nos une em uma fronteira de idas e vindas, e talvez, seria a maré trazendo o entendimento de que não há uma África, como por vezes insistem em afirmar, há por sim, muitas Áfricas, ou melhor, há uma África plural, desvelada em suas literaturas, personagens e recursos linguísticos.

Devido a tamanha multiplicidade, a proposta desta escrita ${ }^{2}$ limita-se a um conversar com uma literatura angolana e a um educar nosso olhar para pensar a infância. Para tanto, busco entrelaçar algumas áreas do conhecimento e infância e agora o movimento é um caminhar pelos estudos literários africanos, para situar, na obra de Ondjaki (escritor estudado), em quais contornos sua obra se ancora.

Primeiramente, importa defender, sem perder de vista o foco dessa discussão, que ao dizer de crianças africanas e seus modos de viver a infância, há o desafio de evitar uma dupla exclusão, visto que só recentemente as crianças têm sido compreendidas como atores sociais e, ainda, porque os estudos da infância surgiram sobretudo na Europa, o

1 Acredito também que tenho a África nascida em mim, e ressalto a escolha, nesta escrita por primeira pessoa, por considerar uma conversa com os saberes africanos, e toda a ancestralidade que me constitui.

2 Discussão presente na dissertação: Lugar da infância: os miúdos narrantes nas obras de Ondjaki. 2015, 238p. Disponível em: https://tede.ufsc.br/teses/PLIT0632-D.pdf. Acesso em: 22 maio 2021. 
que implica abarcar que os modos de viver dessas crianças diferem cultural e socialmente do ocidente. Sustento a importância das investigações qualitativas e participativas que também comportem conhecer a voz das crianças de diferentes continentes e seus modos de viver, a fim de atenuar as distâncias entre seus/nossos saberes.

Retomando o contexto da cultura africana, percorro brevemente a história da literatura de África, no desejo de balizar essa escrita de encontros e marés, e ainda demarcar meu posicionamento quanto às polêmicas acerca da nacionalidade de determinados escritores (quem seria ou não escritor africano), que ao meu entendimento refletem questões políticas e não literárias. Interessa-me, aqui, o valor estético das obras, suas potencialidades, sua força de palavras que, por vezes, tiram-me do lugar. E quanto a essa questão,

[...] não se trata de um esteticismo em si, e sim de iluminar a peculiaridade e as tensões que os textos percorrem, visto serem eles fruto de uma vivência e ambientação africanas, mas vinculados em língua ocidental - portanto, partícipes de uma dupla natureza. (MACEDO, 2010, p. 281)

Afirmo que, pela representação literária, imprime-se a resistência destes povos, perfazendo uma literatura de 
combate, de permanência em suas tradições, memórias e a inegável sequela da colonização. Fanon (1968) discorre sobre essa literatura de combate como sendo a terceira fase de um processo de conscientização do povo através da literatura africana, visando a descolonização:

[...] o colonizado, depois de ter tentado perder-se no povo, perder-se com o povo, vai, ao contrário, sacudir o povo. Em vez de privilegiar a letargia do povo, transformase em despertador do povo. Literatura de combate, literatura revolucionária, literatura nacional. (FANON, 1968, p. 185)

Portanto, essas literaturas de solo africano, seja em GuinéBissau, Moçambique, Cabo-Verde, São Tomé e Príncipe ou Angola, tem suas peculiaridades, temporalidades e distintas experiências históricas que as tornam singulares. Uma cartografia nesse campo literário assinala as diferentes composições políticas, sociais, étnicas e culturais dessas sociedades; e infere que sofreram e reagiram de distintas maneiras quanto à força hostil do colonizador.

Igualmente, posiciono a opção Literaturas Africanas de Língua Portuguesa, renunciando ao termo literatura africana de expressão portuguesa. Anuncio minhas razões: primeiramente pelo lastro colonialista que isso reflete e "por outro lado, dizendo que se trata da expressão portuguesa, 
reduz-se automaticamente o campo de afirmação destas literaturas, impedindo a integração das formas orais das línguas autóctones" (MARGARIDO, 1980, p. 9).

Nesse percorrer, ao sabor das marés, é válido dizer que por muito tempo a história de África foi contada sob as lentes distorcidas do colonizador, dos interesses políticos e financeiros. Entretanto, as literaturas africanas, nascidas em recusa ao pensamento colonial, assumem uma escrita de combate, reivindicação e luta, assumindo "[...] necessidade de falar de sua nação, de compor a frase que exprime o povo, de se fazer porta-voz de uma nova realidade em atos" (FANON, 1968, p. 185).

Seguem no desejo de valorar a africanidade e implodir o discurso colonial. Nesse processo de escrita, sobrevém o compromisso político e de denúncia, a desconstrução gramatical da língua oficial (bela indisciplina ao campo sintático, lexical e morfológico), o empréstimo de línguas nativas e a incorporação de elementos da oralidade.

E aqui, a oralidade alcança uma das experiências culturais africanas e deixa seus sinais, seja pelos recursos linguísticos e estéticos, pela integração de elementos estruturais, seja pela forma como a memória assegura seu lugar de importância e interfere nas narrativas. Portanto, "[...] estamos pensando 
na presença da tradição oral que sutilmente corta essa produção literária. Surge explicita ou implicitamente um tom de conversa sugerindo a interlocução própria da oralidade" (CHAVES, 2000 p. 248).

O sentido da oralidade, aqui apreciado, difere do que se entende no ocidente, pois ultrapassa a voz, é tudo o que o corpo e a memória revelam ao contar, ao partilhar e ao preservar a sabedoria da ancestralidade, a qual é “[...] como o vento: leve, livre e solto, mas tem direção. [...] é o vento assoviando nas folhas, as gotículas de chuva umedecendo a grama, o pio da coruja na mata" (OLIVEIRA, 2007, p. 46).

Logo, esse saber mantido no relato durante anos "[...] pode ser recebido, compreendido e interpretado por ouvidos muito distintos daqueles que estavam destinados no princípio" (AGBOTON, 2004, p. 12)3. Deste modo, as literaturas escritas em língua oficial portuguesa coabitam poesia e luta, escrita e oralidade, o que foi passado e o que poderá ser futuro, constituindo-se em um discurso híbrido e intenso. Inscrevem- se na mesma língua, mas comportam outros espaços, falas outras e tempos outros. E por entre tramas e percursos africanos, apresento o Menino $N$, cuja infância percorre esta escrita.

3 Texto original do espanhol apresentado por minha livre tradução. 


\section{Menino $N$, sua bicicleta e sua carta}

Mas à noite quando olhas as estrelas, podes mesmo explicar aqueles brilhos com palavras de falar?

- Acho que não - ela também falou devagar no ritmo das lesmas.

- O pôr do sol com cor amarelo-torrado, explicas?

- Acho que não. (ONDJAKI, 2012, p. 75)

O tecido narrativo da obra A Bicicleta Que Tinha Bigodes estórias sem luz elétrica ${ }^{4}$ compõe-se entre cheiros, afetos, letras escorregadas de bigodes e uma bicicleta colorida que circula a imaginação das crianças moradoras de certa rua em Angola. Aqui, o Menino $N^{5}$ leva-nos por uma Infância-dizeres, tece um exercício literário de experimentar os segredos e quem sabe as letras guardadas/colecionadas em caixas. Quem sabe, nessa obra, seja possível perceber as tantas brincadeiras da infância, no quintal, na rua... Ou ainda, se possa entender, a exemplo de Manoel de Barros, que "No quintal a gente gostava de brincar com palavras/mais do que bicicleta/principalmente porque ninguém possuía bicicleta" (BARROS, 2003, s.p.).

4 A obra será indicada, no decorrer do texto, com as abreviações ABQTB seguida da referida página, e ainda, seguirá rigorosamente a grafia dos nomes/personagens usada pelo autor. Lembro que a obra foi escolhida pela Fundação Nacional do Livro Infantil e Juvenil Brasileira como o melhor título destinado a crianças e jovens, relativo a 2012. Esta obra já tinha sido distinguida em Portugal com o Prémio Bissaya Barreto de Literatura para a Infância. Disponível em: https://www.publico.pt/2013/05/15/culturaipsilon/noticia/ondjaki-vencepremio-brasileiro-de-literatura-para-criancas-e-jovens-1594541. Acesso em: 22 maio 2021.

5 Apresento um pacto de leitura acerca do Menino N: pode ser considerado Menino Narrador, ou Menino Ndalu. Isso é uma escolha de quem lê... 
Parece-me que, em $A B Q T B$, há uma tentativa do escritor de apresentar esse exercício de sair do lugar e experimentar “[...] um pouco essas zonas mágicas que são de outros, de outros mundos; ecos de coisas que nunca fomos" (ONDJAKI, 2012) ${ }^{6}$. Assim, em linhas iniciais, apresento o tom da escrita da obra, que tem projeto gráfico pelas mãos do ilustrador e caricaturista António Jorge Gonçalves. Mas, com certeza, é o Menino $N$ que tem muito mais para contar.

A narrativa, como já indica o título, tem um enredo circular que avança pela rua, entre os vizinhos e os momentos sem luz elétrica. Ao que o próprio escritor anuncia, ele prossegue na ideia de explorar o modo como as crianças reinventam os momentos sem luz elétrica. "Neste livro misturo isso com outros universos: o da escrita, o da infância e a amizade, entre as crianças, entre crianças e bichos, e entre elas e um escritor" (ONDJAKI, 2012) 7 .

Nos fragmentos que seguem, busco entender como a palavra tece uma infância entre bichos do quintal, amigos, e as travessuras para participar do concurso da Rádio Nacional. Então, também pergunto ao tio Rui (escritor vizinho do Menino

6 Entrevista "Ondjaki: Todo o olhar-de-criança é um poema pronto a explodir" por Márcio Vassallo - julho/2012. Disponível em: http://www.agenciariff.com.br/site/NoticiaEntrevista/ ShowEntrevista/81. Acesso:17 maio 2021.

7 Entrevista "Ondjaki: Todo o olhar-de-criança é um poema pronto a explodir" por Márcio Vassallo - julho/2012. Disponível em: http://www.agenciariff.com.br/site/NoticiaEntrevista/ ShowEntrevista/81. Acesso: 17 maio 2021. 
N): "[...] posso falar dos restos de letras que a Tia Alice tira do seu bigode à noite?" (ABQTB, 2012, p. 6). E nesse encontro com a palavra em Ondjaki, fico a pensar na sensível resposta do tio Rui: “Podes, com palavras pode-se mesmo traduzir a voz do silêncio. Com bigodes e a fazer de guiador uma bicicleta que desce para cima sem travões. Podes, sim, senhor, falar dos restos das letras que, felizmente, andamos a semear" (ABQTB, 2012, p. 7).

Envolvida nessa narrativa, penso na importância do meu ensaiar-se na escrita, do encontro da infância pela palavra, na tentativa de localizar

[...] uma linguagem da experiência, como uma linguagem que modula de um modo particular a relação entre experiência e pensamento, entre experiência e subjetividade, e entre experiência e pluralidade. E tentando pensar, em relação a isso, os limites e as possibilidades de minhas próprias opções de escrita. (LARROSA, 2004, p. 31, grifos meus)

Nesse pensar, convido para a leitura de ABQTB, cujo recurso literário apresenta, nas primeiras páginas, formas verbais no presente, propiciando a ilusão de que é o Menino $N$ que gera um discurso recente e criando (como nas outras obras pesquisadas) uma relação intimista com o leitor: "na minha Rua vive o tio Rui, que é escritor e inventa estórias e poemas que até chegam a outros países muito internacionais" (ABQT, 2012, p. 9, grifos meus). No decorrer da narrativa, o tempo 
verbal muda e, aparentemente, há uma intenção do Menino $N$ a levar-nos por suas histórias: "Era um concurso nacional com primeiro prémio (sic) de uma bicicleta colorida que já apareceu na televisão, mas nesse dia na nossa rua não havia luz" (ABQT, 2012, p. 10, grifos meus).

Na sequência, a narrativa assume o pretérito, aludindo que a história é 'lembrada' pelo Menino $N$, e é apresentada ao leitor como um acontecimento passado (embora não se saiba quando): “Depois do jantar, a luz foi. Estavam já algumas crianças na rua e a Isaura veio também. Era sempre assim [...]" (ABQT, 2012, p. 17, grifos meus).

$\mathrm{O}$ anfitrião $\mathrm{N}$ leva-nos também por contornos a serem descobertos através da brincadeira das palavras, as existências outras, as relações com a natureza:

Ouvi os passos dos chinelos da Avó bem devagar, vi as primeiras luzes da manhã. Um dia alguém disse que aquela era uma luz muito fresca, eu ria de ouvir essas frases dos poetas "luz fresca", como a água da Avó a regar as plantas verdes da manhã, isso quando a água vinha. Se a água não viesse, a minha avó, que é muito engraçada, regava mesmo assim. (ABQTB, 2012, p. 39)

É possível perceber, na sequência do enredo, a evidência muito mais que nas outras obras, do cenário rua, ou seja, 
o cotidiano acontece na escuridão bonita ${ }^{8}$ da rua, entre as histórias contadas, por encontros das pessoas na rua e no muro perto da casa do tio Rui e da avó Agnete, ou melhor, da Avó Dezanove. É possível, nessa leitura, captar nuances reveladoras de uma infância vivida sim entre a casa e a rua, como se ela (a rua) fosse continuação do quintal, lugar de momentos e de contos. E a esses indícios, soma-se a memória do escritor:

Quase sempre saíamos para a rua. Para encontrar as outras crianças do meu bairro, para inventar brincadeiras. No bairro da minha Avó Agnette, na Praia do Bispo, existiam ainda mais possibilidades. Uma delas chamava-se "cinema bú." Consistia em esperar reflexos dos carros que passavam para inventar estórias que logo em seguida narrávamos aos outros. O que a falta de luz fazia, na realidade, era estimular a criatividade e a imaginação. Isso era muito bom. (ONDJAKI, 2012) ${ }^{10}$

8 Referência à obra Uma escuridão bonita (ONDJAKI, 2013).

9 Aqui remeto ao momento que de fato fez parte das memórias de infância do escritor. Partilho no fragmento da obra Momentos de Aqui (2002), as revelações do que era o cinema bú, em indiscutível momento da bela imaginação das crianças:

“Estávamos sentados na varanda a ver o cinema bu. Era o cinema mais barato e imaginário que conhecíamos. Acontecia quando faltava luz. Íamos para a varanda e virávamo-nos para a parede. De longe, os carros que passavam injectavam na noite o poder luminoso dos seus faróis. Esses jactos (sic) de luz partiam do carro, passavam pelo arvoredo do jardim da nossa casa e projectavam (sic) sombras na parede. Essas sombras eram a alma do cinema bú. A interpretação era nossa. (ONDJAKI, 2002, p. 88-89)

Vale o registro de que o "CINEMA BÚ" aparece também em "Uma escuridão Bonita", e agora o Menino $N$ já é um menino crescido, mas o cinema $\mathrm{Bu}$, ainda permanece.

10 Entrevista "Ondjaki: Todo o olhar-de-criança é um poema pronto a explodir" por Márcio Vassallo - julho/2012. Disponível em: http://www.agenciariff.com.br/site/NoticiaEntrevista/ ShowEntrevista/81. Acesso: 14 maio 2021. 
Já em ABQTB, muito próximo ao vivido por Ondjaki, é o Menino $N$ que mobiliza os personagens que compõe a obra e conta cenas, como quando "às vezes mesmo o tio Rui também vinha cá fora ouvir a nossa conversa e ficar a rir, depois anotava as coisas que as crianças diziam nessas folhas de papel amarelo" (ABQTB, 2012, p. 17, grifos meus). Aqui, o menino referencia o Tio Rui ${ }^{11}$ e indica que esse adulto tem forte ligação com o menino e com as crianças. A partir de seu olhar atento e sensível, consegue aproximar-se das crianças e, como indico no grifo, ele ouve, importa-se com esse universo improvável da infância. É com ele que acontece o belo diálogo sobre silêncios e sobre 'o outro':

- Tio Rui, os silêncios afinal servem para quê?

- Para as pessoas estarem umas com as outras.

- Não basta estarmos sentados no mesmo lugar?

- Não. [...] É preciso olharmos para o outro. (ABQTB, 2012, p. 63, grifos meus)

Esse adulto, dentro da narrativa, é um dos que acessam o universo das crianças, atravessa do tempo khrónos (sucessivo, mensurável) para o tempo aión (temporalidade não numerável, da ordem da intensidade) (KOHAN, 2010) e

11 Personagem que aparece em sonho em Avó Dezanove e o segredo do soviético: “[...] até o Tio Rui que era escritor passeava numa bicicleta que tinha uns bigodes desenhados e ele fazia as duas coisas, conduzia a bina (bicicleta) e dominava o papagaio - que bicicleta bonita! -." (ONDJAKI, 2009, p. 72). 
assim constitui uma relação de confiança entre as crianças. Elas também o olham, observam e o convocam para suas singularidades. E é Isaura, amiga e vizinha de $\mathrm{N}$, quem confirma que as crianças também nos olham:

- O tio Rui, à tarde, fica na varanda dele a escrever. Primeiro pensa, depois fala em voz alta e depois é que escreve.

- Como é que sabes que ele tá a pensar?

- És burro ou quê? - a Isaura olhou para mim espantada. - Não sabes que quando os mais velhos coçam muito tempo o bigode é porque estão a pensar? (ABQTB, 2012, p. 14-15)

E fico a rever nossos passos entre as crianças, entre as instituições coletivas de educação, lugares de convivências (entre crianças e crianças, crianças e adultos e adultos e adultos). Reflito acerca das maneiras de percorrer as lógicas infantis, nossos modos de perceber esses olhares outros, esse percurso do outro que também me olha. Penso nessa alteridade tão discutida na Educação e que nos faz repensar as práticas e as relações construídas por entre infâncias e espaços. Lugares de possibilidades, de conhecer as crianças e o mundo que as cerca, suas interpretações, suas diferentes óticas. Possibilidades de travar conversas como esta:

- Gostas de estrelas?

- Gosto bué, tio Rui. Brilham sem gastar a pilha. Só nunca consegui entender a cor delas.

- As estrelas não têm cor, são como as pessoas. 
- Eu pensei que a cor das pessoas ficava na pele delas.

- Não. A cor das pessoas fica nos olhos de quem as olha... (ABQTB, 2012, p. 85)

Esses fragmentos fazem-me refletir quanto à possibilidade de um olhar atento para tempo e infância, algo que revele o não numerável da criança (etapa), mas sim a intensidade da duração dos momentos, da vida por si, ou seja, um tempo aiônico, imensurável. Talvez seja o adulto Ondjaki a localizar tempos e vozes da infância e que evoca: "As coisas urgentes, aquilo que chamo de urgências literárias, são vozes ou preocupações, ou até convicções, que aparecem quase independentes da estória que se escreve" (ONDJAKI, 2012). ${ }^{12}$

Essas vozes que falam, segredam, na escuridão da rua, anunciam o entendimento do tempo aión ${ }^{13}$, que se faz pela ordem da ruptura e se constitui pela intensidade, e talvez anuncie pensar tempos outros para a infância e para nós. E é desse lugar, desse tempo, presente no cotidiano, que mesmo diante da escuridão, o Menino opera seus 'truques': "passado um bocadinho, mesmo no escuro, eu já via tudo. Era esse o truque, esperar um bocadinho, fechar os olhos com força e depois vê-se bem mesmo no escuro" (ABQTB, 2012, p. 37).

12 Entrevista "Ondjaki: Todo o olhar-de-criança é um poema pronto a explodir" por Márcio Vassallo - julho/2012. Disponível em: http://www.agenciariff.com.br/site/NoticiaEntrevista/ ShowEntrevista/81. Acesso: 12 maio 2021.

13 Acredito que pelas mãos de um tempo aión, que se faz pela ordem da ruptura e se constitui pela intensidade, seja possível pensar tempos outros para a infância e para nós. 
A dimensão de acontecimentos, da experiência intensa, especialmente quando a luz 'falta', é revelada, também pelas mãos do Menino N:

Quando a luz vai, as conversas de rua ficam mais mágicas: os olhos tipo que brilham de outra maneira, as pessoas saem à rua e ficam imaginando o que poderia estar a acontecer na telenovela, [...] a minha avó fica no muro a rir das nossas estórias ou contam também uma estória de antigamente, [...] ficamos contentes porque podemos fazer mil coisas fora do ritmo normal (?) das nossas vidas. (ABQTB, 2012, p. 52-53)

Essa forma de apreender o mundo, fora dos ponteiros do relógio, fora do tempo 'normal', leva-me a questionar de que normalidade esse menino fala? Creio que ele indica uma dominação da ótica adulta, algo a revelar que o tempo pode e deveria ser medido de outra forma, talvez assim: "Aquela era a hora de os sapos atravessarem a rua e irem beber água numa lagoazinha de água parada [...]" (ABQTB, 2012, p. 19).

Essa cena sobre a hora dos sapos acontece entre o Menino $N$ e Isaura e exala, para além das relações com os seres (animados ou inanimados), afinidade entre os dois. É Isaura a menina de ideias complicadas e que "fica muito tempo sentada no quintal dela a olhar as andorinhas, as lesmas e até conhece cada gafanhoto do jardim dela" (ABQTB, 2012, 
p. 14). É que me afeta e por ela penso no que de fato é possível aprender com as tantas outras formas de existência no mundo, é por ela que reflito acerca dos diferentes tempos de aprendizado e emprestando palavras de Manoel de Barros $^{14}$, penso que não devemos, não podemos acelerar a importância das coisas. Por ela, que não sabia a tabuada, penso no que entendemos como outras formas do saber:

- Quatro vezes quatro? - perguntava - CamaradaMudo quando ainda dava explicações de matemática.

- Não sei, mas por exemplo, o gafanhoto Samora Machel gosta mais das plantas da casa do tio Rui, e só come antes das onze. Se está muito sol, vai-se esconder. [...]

- Seis vezes três?

- Não sei, mas a lesma Senghor é muito estranha porque anda a fazer uma casa com pedrinhas que vai buscar no fundo do quintal e um dia destes pode ser pisada. (ABQTB, 2012, p. 14-15)

A personagem é, segundo o escritor, uma homenagem a Isaura do conto Nós matamos o Cão Tinhoso. Vale dizer que o Menino $\mathrm{N}$, tem particular admiração pela Isaura de $A B Q T B$, pois a forma como ela expressa sua preocupação com os animais é motivo de encantamento. A menina, de grande sensibilidade, torna-se, como diz o Tio Rui 'parente

14 Poetanto: "Que a importância de uma coisa há que ser medida pelo encantamento que a coisa produza em nós. Assim um passarinho nas mãos de uma criança é mais importante para ela do que a Cordilheira dos Andes" (BARROS, 2006, s.p.). 
por aproximação afetiva' dos animais. Ela nomeia os animais que circulam em seu quintal e isso, aos olhos do leitor tem um tom humorado e ao mesmo tempo uma sutileza política:

O gato dela se chama Ghandi, acho que era um senhor tipo indiano ou quê. $O$ cão se chama AmílcarCabral (sic), até Ihe chamamos de Amílcar-Cãobral (sic). A lesma é Senghor, os gafanhotos são Samora, Mobutu e Khadafi, os sapos se chamam Raúl (sic) e Fidel. Parece que também deu nomes aos passarinhos mas nunca consegui decorar a lista toda. (ABQTB, 2012, p. 15)

É possível dizer, a partir da sensibilidade de Isaura, que ela 'coleciona' os animais do quintal e, portanto, indica a ideia benjaminiana de infância, que em

cada pedra que eu achava, cada flor colhida, [...] já era para mim começo de uma única coleção, e tudo o que, em geral, eu possuía, formava para mim uma única coleção [...] Era assim que cresciam e se mascaravam os haveres da infância, em gavetas, arcas e caixas. (BENJAMIN, 2012, p. 126)

Penso se seria somente a Isaura que coleciona, penso se nós também, adultos andantes entre crianças, não teríamos também outras caixas de coleções, formadas em cada dia, em cada vivência, em cada situação de afetos e de respeito. Assim, "A história de cada um vai sendo reunida e só pode ser contada por quem conhece os significados de cada uma dessas coisas, 
que evocam situações vividas, conquistas ou perdas, pessoas, lugares, tempos esquecidos" (KRAMER, 2009, p. 171).

Voltando ao que Isaura enuncia, contemplo que seu respeito pelos animais é muito bem entendido pelo Tio Rui, que intervém no atropelamento do sapo Raúl (sic) e solenemente acolhe os sentimentos da menina. Outro adulto que apresenta muito respeito pelas crianças é a avó do Menino $N$, que no enterro do sapo, surge na lagoa iluminada pelas velas, segura a mão de Isaura, e em gesto de cumplicidade e respeito à criança fala: "Vais dizer umas palavras, Isaura? Só se for um poema. Pode ser. Acho que sapos também gostam de poesia" (ABQTB, 2012, p. 29). Embora, no cerimonial tenham comparecido alguns adultos, Isaura afirma que "Enterro de bichos é coisa de criança. Os adultos não entendem e depois só querem nos gozar" (ABQTB, 2012, p. 27).

Nessas duas situações, fico a refletir acerca da imagem que o adulto representa para as crianças e especialmente quais adultos são/estão autorizados a ingressarem nesse mundo paralelo, construído diariamente. Penso o quanto essa permissão das crianças nos é urgente, algo que nos possibilite perceber o inatingível, que "[...] nos remete a dobra do que somos e não somos, do que podemos e não podemos, multiplicando-nos num outro tempo e espaço possível" (LIMA, 2008, p. 120). 
A situação do funeral do sapo apresenta sensibilidade, por parte das crianças e respeito dos adultos que foram autorizados a participar. E imbuídos pela noite, o Menino $\mathrm{N}$ descreve o lugar de forma quase tocável, sob o entendimento da fala dos animais, sob a luz dos pirilampos, que somente as crianças conseguem colorir mesmo sem luz: "Os pirilampos não paravam. Um acendia, o outro também. Devagar, rápido, e em ritmos trocados. Não sei explicar, mas parecia que usavam a luz para falar um com o outro" (ABQTB, 2012, p. 36). Essa percepção do entorno e da imaginação acontece também, sob o olhar do Menino N, em: "Mesmo a Isaura uma vez me disse que naquela lagoa ela já tinha visto gambozinos ${ }^{15}$ coloridos a imitarem um arco-íris" (ABQTB, 2012, p. 19).

A narrativa, tendo como cenário a rua, circunda um concurso literário anunciado pela Rádio Nacional, cuja premiação consiste em "[...] uma bicicleta bem bonita, amarela, vermelha e preta [...]" (ABQTB, 2012, p. 10), ou seja, cores da bandeira angolana. E o Menino $N$, tomado pelo desejo da bicicleta, sugere aos miúdos que o Tio Rui escreva a redação. A bicicleta é um anseio do Menino $N$, pois ele promete a si mesmo que se ganhasse, emprestaria a todos da rua, sem pedir nada em troca. "Essa promessa assim bem dura de fazer é que me fazia acreditar que

15 Apresento minha escolha de significado: são seres imaginários que vivem no campo e algumas espécies também se encontram nos parques de algumas cidades. 
eu ia mesmo ganhar a bicicleta" (ABQTB, 2012, p. 10). Ele e os amigos buscam estratégias para a redação, afinal o tio Rui era escritor e sempre tinha ideias, então: "Toumasé a pensar que deveríamos pedir patrocínio no tio Rui, aquele que escreve bué ${ }^{16}$ de poemas" (ABQTB, 2012, p. 11).

A tarefa de escrever revela-se difícil, porque o tio Rui rejeita a proposta de escrever pelas crianças e a inspiração não aparece. Diante da dificuldade de uma boa ideia para a escrita, é Isaura que apresenta "uma ideia para conseguirmos uma boa estória" (ABQTB, 2012, p. 33). A estratégia seria ter a caixa 'mágica' do Tio Rui, que continha o segredo dos bigodes do tio, pois ao serem cortados, "[...] aquilo acontecia: pequenas letras caíam do bigode para a caixa, eram vogais de 'a', 'e', 'i', 'o', 'u', mas também sobras de 'k' e ' $w$ ', alguns ' $t$ ' e dois ' $h$ '. Ela (a esposa Alice) escovava e a caixa guardava aquelas letras soltas" (ABQTB, 2012, p. 48).

Assim, segundo o que pensam as crianças, de posse da caixa, eles conseguiriam escrever uma boa história e ganhar o concurso. A caixa passa a povoar os pensamentos do Menino $N$, e mesmo durante a noite pensa que "[...] aquela caixa tinha só restos de palavras, bocadinhos de sonhos, letras que nunca conseguiram ser palavras nem mesmo frases de o tio Rui escrever os livros dele" (ABQTB, 2012, p. 39).

16 Grande número ou quantidade. 
O Menino $N$ e os amigos JorgeTemCalma e Isaura envolvem-se em uma maneira de aproximarem-se da caixa. Essa situação leva-os para, durante a noite, fazer uma visita na casa do Tio Rui. O JorgeTemCalma distrai a atenção e sob um momento de suspense o Menino $N$ consegue ter nas mãos a caixa, e espreitar 'bem devagarinho'. Nessa cena, parece que o silêncio envolve o menino e também o leitor:

Uma quase magia me fez comichão nas mãos: a caixa tinha veludo lá dentro e letras brilhantes faziam um barulho que eu não podia ouvir. Acentos circunflexos estavam num canto, uns em cima dos outros, como chapéus de palha chineses, havia cedilhas no meio, muitos ' $k$ ', muitos ' $p$ ' e dois ' $w$ '. Tive medo de tocar ou mesmo de deixar cair a caixa, então soprei devagarinho. (ABQTB, 2012, p. 65)

Assim, como quando se sopra velas de um bolo e se faz um pedido, o sopro do menino estava envolto no desejo de que as letras se espalhassem sobre Luanda, e especialmente, que ajudassem na escrita da redação do concurso, pois só restava um dia para o prazo de entrega das redações. Desejo de que as ideias viessem, e, sob a ótica infantil, que a tarefa de escrever para o concurso fosse realizada. Vale registrar que a cena do sopro, é banhada por lirismo e traços de beleza: "O brilho aumentou a mudar de 
cor com a velocidade bonita das estrelas. As minhas mãos tremiam como o mar quando engole o sol devagarinho" (ABQTB, 2012, p. 65).

O Menino $N$ é surpreendido pela voz do tio Rui e sai correndo, deixando a caixa. Chega à casa da avó com o coração aos pulos, ela lembra que o prazo do concurso esgota no dia seguinte e oferece: “- Queres que acenda aquela vela boa, para escrever a tua estória? - Quero sim, Avó" (ABQTB, 2012, p. 66). Assim, o menino passa a noite a escrever, no dia seguinte a redação é entregue na portaria da Rádio Nacional e nasce a espera do resultado.

As outras crianças cobram do Menino $N$ como era a estória e diz simplesmente: “- Não foi bem uma estória. Só consegui mesmo escrever uma espécie de carta" (ABQTB, 2012, p. 70). E o suspense permanece até o momento do resultado, que seria ouvido pelo rádio da casa do tio Rui. Antes do resultado, financiados pelo tio Rui vão comprar gelados ${ }^{17}$, seguem correndo pela rua, com a tranquilidade de quem conhece 0 caminho e faz da rua seu cotidiano, porções do vivido. Seguem "[...] a saltar buracos nos passeios, a desviar dos carros antigos e abandonados. A olhar para o céu onde dançava parado um papagaio de papel que tinha ficado preso na antena de um prédio [...]" (ABQTB, 2012, p. 73). 
Nessa cena, em condição de ligeira liberdade (LIMA, 2008), - Menino $N$ e seus amigos percorrem a rua, como se fosse o quintal de casa, tamanha intimidade que possuem com a rua, isso parece refletir no que o escritor diz de sua memória da infância vivida pelas ruas do bairro.

Nessas possibilidades do vivido, o Menino $N$ carrega a expectativa do resultado do concurso, que infelizmente não acontece como o esperado. A estratégia que ele usou para o concurso reflete também uma inocência, uma forma de entender o mundo sem fronteiras de hierarquias, porque o que ele escreve é um pedido direto ao Presidente do país: “- Era um pedido mesmo. Para o camarada presidente dar bicicletas a todas as crianças de Angola, mesmo as que não sabem contar estórias. Como eu..." (ABQTB, 2012, p. 84).

E passada a tristeza do menino, o livro finaliza com o diálogo do tio Rui, exalando um tom político e ao mesmo tempo levando o leitor a um desfecho poético:

$$
\begin{aligned}
& \text { - Tio Rui, as estrelas têm dono? } \\
& \text { - Têm, sim. } \\
& \text { - São de quem? } \\
& \text { - São do povo. (ABQTB, 2012, p. 86) }
\end{aligned}
$$

A obra, embora o insucesso do concurso, em nenhum momento é uma narrativa triste, muito pelo contrário, "é feliz, bonita, em torno da amizade, da criatividade. E não só 
entre as crianças, mas entre as crianças e os mais velhos" (ONDJAKI, 2013) ${ }^{18}$. Vale registrar que o escritor 'presenteia' o leitor com um achado na contra capa do livro: a carta encontrada nos arquivos da Rádio Nacional:

Este postal não é a estória que a Rádio Nacional pediu e o meu nome não vou dizer porque eu quero pedir uma coisa que não é para mim mas para muitas crianças mas se o camarada presidente quiser (sic) mesmo assim me dar uma bicicleta com as cores da bandeira, eu sou neto da AvóDezanove, é só vir aqui na minha rua perguntar onde ela mora, eu sou amigo da Isaura (a dona do Cãobral) e do JorgeTemCalma. (ABQTB, 2012, contracapa)

A singeleza da carta e a inocência do menino em escrever para o Presidente, na certeza de que será lido, fazem com que o leitor tenha certa cumplicidade com o Menino $\mathrm{N}$ e envolva-se com as linhas da escrita. O tom de intimidade do menino também aparece em: "Boa noite camarada presidente, dorme bem!" (ABQTB, 2012, contracapa). E, ainda, em "Como diz a minha AvóDezanove, bons sonhos e felis (sic) noite, camarada presidente." (ABQTB, 2012, contracapa). A autenticidade e a sinceridade à flor da pele, típica das crianças, são o dizer do mundo, entre sabores

18 Reportagem "Ondjaki vence prémio brasileiro de literatura para crianças e jovens" por Rita Pimenta - maio/2013. Disponível em: https://www.publico.pt/2013/05/15/culturaipsilon/ noticia/ondjaki-vence-premio-brasileiro-de-literatura-para-criancas-e-jovens-1594541. Acesso: 19 maio 2021. 
e saberes. Isso, naturalmente, leva o Menino $N$ a dizer: "É verdade: desculpa só se este postal tem muitos erros da ortugrafia (sic), a minha disciplina preferida é educação fízica (sic)" (ABQTB, 2012, contracapa).

É inegável a esperteza do Menino $N$, que escreve a carta, não diz seu nome, mas oferece todas as dicas de onde mora, assim, se alguém ler a carta e quiser dar a bicicleta, já saberia onde encontrá-lo. E ainda, a solidariedade franca, quando diz "[...] aqui na rua estamos a dividir bem as coisas [...]" (ABQTB, 2012, contracapa), faz com que o leitor, a meu ver, acalente uma vontade de que o menino receba a tão sonhada bicicleta.

E a carta chega ao fim, assim como este escrita com a imagem da bicicleta com bigodes, que a meu ver, representaria toda a realização de um desejo, a força da fantasia, da liberdade, de um imaginário outro. Então, "[...] se na tua casa tem janelas espreita só porque hoje não tem lua mas as estrelas estão muito bonitas[...]" (ABQTB,2012, contracapa).

\section{De um aceno e um até breve}

As palavras que compuseram esta escrita nortearam uma discussão acerca da literatura e da infância, no sentido de pensar em uma educabilidade do olhar, em aportes teóricos, em cenas literárias e em reflexão do que a infância nos educa. Entre outros fios, por outras linhas, tive o 
Menino N como anfitrião nessas terras de infâncias vividas e experienciadas em lugares possíveis e impensados (por mim), em mobilidade de conceitos. Assim, em dissolução de fronteiras, em desprendimento das muitas certezas e morais, em reinvenção de normas, em ruptura de medos e entrega à imaginação, compreendo, então, que infância é um brincar com a seriedade e sisudez do adulto, é mudar os significados de lugar, reinventar sentidos, delirar o verbo e colorir o que se vê. Essas relações são constituídas a partir de singulares e múltiplas experiências que configuram os contextos infantis, já que a criança, diariamente, expressa e confirma sua mobilidade no mundo, o quanto dizem, o quanto surpreendem e como tratam o tempo. E, quanto ao tempo, as (tantas) infâncias, ofereceram-me a temporalidade aiônica, ou seja, descontínua, circular e de afirmação intensiva. No desenrolar das narrativas, acionaram sob as lentes da infância, seus modos de existência, interrompendo tempos padronizados pelas convenções adultocêntricas, nos quais não há, na maioria das vezes, espaços para outros olhares possíveis.

\section{Referências}

AGBOTON, Agnès. Na mitón: la mujer em los cuentos y leyendas africanos. Barcelona: RBA libros, 2004.

BARROS, Manoel de. Escova. Memórias inventadas: A infância. São Paulo: Planeta, 2003. 
BARROS, Manoel de. Memórias inventadas: a segunda infância. São Paulo: Planeta, 2006 [não paginado].

BENJAMIN, Walter. Rua de mão única Tradução de Rubens Rodrigues Torres Filho e José Carlos Martins Barbosa. São Paulo: Brasiliense, 2012.

CARVALHO, Ruy Duarte. A decisão da idade. Luanda: União dos Escritores Angolanos, 1976.

CHAVES, Rita. O Passado Presente na Literatura Angolana. SCRIPTA. Belo Horizonte, v.3, n.6, p. 245-257, 1ㅇ semestre de 2000.

FANON, Frantz. Os condenados da terra. Tradução de José Laurênio de Melo. Civilização Brasileira: Rio de Janeiro, 1968.

KOHAN, Walter Omar. Vida e morte da infância, entre o humano e o inumano. Educação e Realidade, Porto Alegre, v. 35, n. 3, p. 125-138, setembro/dezembro de 2010. Disponível em: https://seer.ufrgs.br/ educacaoerealidade/article/view/13083. Acesso em: 22 maio 2021. KRAMER, Sonia. Infância, memória e saber - considerações à luz da obra de Walter Benjamin. In: KRAMER, Sonia. A criança e o saber. Rio de Janeiro, v. 1, p. 245-249, 1999.

LARROSA, Jorge. A operação ensaio: sobre o ensaiar e o ensaiar-se no pensamento, na escrita e na vida. Educação \& Realidade, v. 29, n. 1, (2004). Disponível em: https://seer.ufrgs.br/educacaoerealidade/article/ view/25417. Acesso em: 23 maio 2021.

LIMA, Patrícia de Moraes. Infância e experiência: as narrativas infantis e a arte-de-viver o cuidado. 2008.Tese (Doutorado em Educação) Universidade Federal do Rio Grande do Sul, 2008. Disponível em: http:// lume.ufrgs.br/handle/10183/15340. Acesso em: 22 maio 2021.

MACEDO, Tânia. O ensino das literaturas africanas de língua portuguesa no Brasil: algumas questões. In: SECCO, Carmen Tindó Secco; JORGE, Silvio Renato; SALGADO, Maria Tereza (Orgs.). África, escritas literárias: Angola, Cabo Verde, Guiné-Bissau, Moçambique, São Tomé e Príncipe. Rio de Janeiro: editora UFRJ; Angola: UEA, 2010.

MARGARIDO, Alfredo. Estudos sobre literaturas das nações africanas de língua portuguesa. Lisboa: A regra do jogo, 1980. 
OLIVEIRA, David Eduardo de. Filosofia da ancestralidade: corpo e mito na filosofia da educação brasileira. Curitiba: Editora Gráfica Popular, 2007. ONDJAKI. Momentos de aqui. Colecção letras angolanas. Luanda: Editorial Nzila, 2002.

ONDJAKI. AvóDezanove e o segredo do soviético. São Paulo: Cia das Letras, 2009.

ONDJAKI. A bicicleta que tinha bigodes. Rio de Janeiro: Pallas, 2012. ONDJAKI. Uma escuridão bonita. Rio de Janeiro: Pallas, 2013.

\section{Izabel Cristina da Rosa Gomes dos Santos}

Doutora em Literatura Africana vinculada ao Programa de Mestrado em Literatura, linha "Subjetividade, Memória e História" da Universidade Federal de Santa Catarina/UFSC.

Professora do curso de Pedagogia pelo Centro Universitário Municipal de São José/USJ.

Integrante do Núcleo NUVIC (Núcleo Vida E Cuidado: Estudos e Pesquisas Sobre Violências)-UFSC, e Núcleo GRIOT (Núcleo de Estudos de Poéticas Musicais e Vocais)-UFSC.

E-mail: belgomes2712@gmail.com

Lattes: http://lattes.cnpq.br/0807267168147199 